\title{
QUEEN'S
UNIVERSITY
BELFAST
}

\section{A novel methodology to characterize the constitutive behaviour of polyethylene terephthalate for the stretch blow moulding process}

Yan, S., Menary, G., \& Nixon, J. (2017). A novel methodology to characterize the constitutive behaviour of polyethylene terephthalate for the stretch blow moulding process. Mechanics of Materials, 104, 93-106. https://doi.org/10.1016/j.mechmat.2016.10.006

\section{Published in:}

Mechanics of Materials

\section{Document Version:}

Peer reviewed version

Queen's University Belfast - Research Portal:

Link to publication record in Queen's University Belfast Research Portal

Publisher rights

(c) 2016 Elsevier Ltd. This manuscript version is made available under the CC-BY-NC-ND 4.0 license http://creativecommons.org/licenses/by$\mathrm{nc}-\mathrm{nd} / 4.0 /$, which permits distribution and reproduction for non-commercial purposes, provided the author and source are cited.

\section{General rights}

Copyright for the publications made accessible via the Queen's University Belfast Research Portal is retained by the author(s) and / or other copyright owners and it is a condition of accessing these publications that users recognise and abide by the legal requirements associated with these rights.

Take down policy

The Research Portal is Queen's institutional repository that provides access to Queen's research output. Every effort has been made to ensure that content in the Research Portal does not infringe any person's rights, or applicable UK laws. If you discover content in the Research Portal that you believe breaches copyright or violates any law, please contact openaccess@qub.ac.uk. 


\title{
A Novel Methodology to Characterize the Constitutive Behaviour of Polyethylene Terephthalate for the Stretch Blow Moulding Process
}

\author{
Shiyong Yan a, ${ }^{a}$, Gary Menary ${ }^{a}$, James Nixon ${ }^{a}$ \\ a Queen's University Belfast, Advanced Manufacturing \& Processing, School of Mechanical \& \\ Aerospace Engineering, Ashby Building, Stranmillis Rd, Belfast, UK
}

\begin{abstract}
The stretch blow moulding (SBM) process is the main method for the mass production of PET containers. And understanding the constitutive behaviour of PET during this process is critical for designing the optimum product and process. However due to its nonlinear viscoelastic behaviour, the behaviour of PET is highly sensitive to its thermomechanical history making the task of modelling its constitutive behaviour complex. This means that the constitutive model will be useful only if it is known to be valid under the actual conditions of interest to the SBM process. The aim of this work was to develop a new material characterization method providing new data for the deformation behaviour of PET relevant to the SBM process. In order to achieve this goal, a reliable and robust characterization method was developed based on an instrumented stretch rod and a digital image correlation system to determine the stress-strain relationship of material in deforming preforms during free stretch-blow tests. The effect of preform temperature and air mass flow rate on the deformation behaviour of PET was also investigated.
\end{abstract}

\section{Keywords}

Material Characterization, Polyethylene terephthalate, stretch blow moulding, instrumented stretch rod, digital image correlation, membrane stress 


\section{Introduction}

Nowadays, due to the continuously increasing market value of the beverage bottle industry, there is an aim to optimize all the elements within the ISBM process to reduce the cost. For instance, to design the geometry of preforms and to reduce the material weight; to recycle the air to reduce the energy cost for high pressure; and to design the infrared oven to save the energy cost for reheating.

In order to achieve these optimizations, numerical simulations are essential to be used to obtain a better insight into the process operation in order to identify the critical process conditions which give a product with optimum quality [1]. For a simulation to be accurate the material model used and process parameters used in the simulation have to be accurate and validated. One of the important tasks in numerical simulations of the stretching blow moulding process is to model the constitutive behaviour of PET, which is complicated because the responses are typical nonlinear viscoelastic and therefore highly sensitive to thermomechanical history. This means that the constitutive model will be useful only if it is known to be valid under the actual conditions of the SBM process of interest [2].

In the blow moulding process, the material typically experiences a high speed, large strain biaxial deformation. Numerous researchers world-wide have developed their own test platforms and enabled significant advances to be made in understanding the evolution of microstructure in PET materials under processing conditions [3-9], and to generate stress strain data that is suitable for developing and validating constitutive material laws [10-13].

However, it is recognised that biaxial testing does have serious limitations. Firstly, the test speed of the biaxial stretching testing machine is relatively low compared to the average deformation speed of material in the SBM process, which was found to be 50/s [14]. Secondly, almost all designs of biaxial stretching testing machine require test specimens to be in the form of thin square sheets, plaques or crucifix. In the case of injection stretch blow moulding, where no sheet is produced, industrial samples cannot be tested directly and equivalent sheet specimens have to be specially prepared. This causes problems in characterization to ensure that the test specimen has similar thermomechanical history and properties to the preform.

Another technology, Digital Imaging Correlation (DIC), has begun to provide researchers in polymer processing with an additional, more direct and immediate means of tracking the response of materials during processing. One of the first to apply this technology to blow moulding was Billon et al. who have conducted several studies using a free blow device in conjunction with a single high speed camera [15]. They used surface grids to assess the 
evolution of strain rate in the preform during blowing for different conditions and correlated this with separate microstructure measurements. Menary et al. have also collaborated with Billon in using the device to validate ISBM simulations [16] by comparing images of the evolving preform at specific time points with simulation. Billon [17] proposed a methodology for characterising PET resin using their device by comparing the volume of the final blown preform to tensile tests and Dynamic Mechanical Analysis of samples taken from the final preform. Zimmer et al [18] used 3D DIC to determine the stress strain behaviour from a free blown preform and use the data to validate a material model. However, these experiments did not include a stretch rod resulting in the likelihood of process instabilities and like the work of Billon they provided limited capacity for heating and flow control.

The goal of this research is to develop a new characterization method to obtain the constitutive behaviour of the material for the ISBM process directly from the preform and under conditions which are typically used in industry.

\section{Free stretch-blow (FSB) process with integrated instruments}

A free stretch-blow test is similar to a SBM test wherein the preform is heated firstly above the $\mathrm{Tg}$ of PET material, after which the hot preform enters the blowing stage where it is stretched by a stretch rod and freely blown with pressurised air without a mould. The evolution of an inflating preform can be observed and studied. The free stretch-blow experiments offer the opportunity to investigate the process in much more detail than can be found when inflating a preform inside a closed mould.

All FSB trials were performed on a single cavity, laboratory-scale stretch blow mould machine supplied by Vitalli \& Son and located at Queen's University Belfast (QUB). The preforms were pre-heated using a Grant ${ }^{\mathrm{TM}}$ general purpose stirred thermostatic bath from $95^{\circ} \mathrm{C}$ to $110^{\circ} \mathrm{C}$ by completely immersing the preform and constantly rotating it inside the oil bath to obtain a uniform temperature profile. The pre-blow pressure was fixed at $0.8 \mathrm{MPa}$ for these trials. The air flow providing preform inflation for the SBM process is a combination of both supply pressure and adjustment of the flow restrictor. With the supply pressure fixed at $0.8 \mathrm{MPa}$, the flow restrictor (ranged 0 - closed to 6 - fully open) was adjusted to two settings: 2 and 6, indicating low mass flow rate (MFR) and high MFR respectively and corresponding air mass flow rate of $9 \mathrm{~g} / \mathrm{s}$ and $34 \mathrm{~g} / \mathrm{s}$. The detailed description of the experimental setup is described by Nixon et al [19].

An instrumented stretch rod [20] which is able to measure the cavity pressure evolution within the deforming bottle and the reaction force applied on the tip of the stretch rod has 
been employed. The sensitivity in force and pressure is $0.798 \mathrm{~N}$ and $1.313 \mathrm{kPa}$ respectively. The stretch-rod displacement is measured using a linear variable differential transformer (LVDT). The LVDT sensor used is an ACT6000C supplied by RDP Electronics. The typical outputs of one free stretch-blow test can be found in Figure 1. From this figure, one can find the preform expanding in 4 stages. From 0 s to $0.12 \mathrm{~s}$, the preform is deformed entirely by stretch rod displacement. The linearly increasing force curve indicates the elastic response of the material. Then the preform experiences a rapid inflation from $0.12 \mathrm{~s}$ to $0.18 \mathrm{~s}$, when the air mass flow rate is lower than the volumetric increase rate resulting in the reduction in both cavity pressure and reaction force. The next stage is from $0.18 \mathrm{~s}$ to $0.36 \mathrm{~s}$ when the preform expands isobarically, resulting from the coincidence between the air mass flow rate and the volumetric increase rate. From 0.36 s to the end of the process is the last stage where the cavity pressure starts to increase again. This pressure increase indicates that the volumetric expansion rate reduces, indicating the material has entered the strain hardening phase.

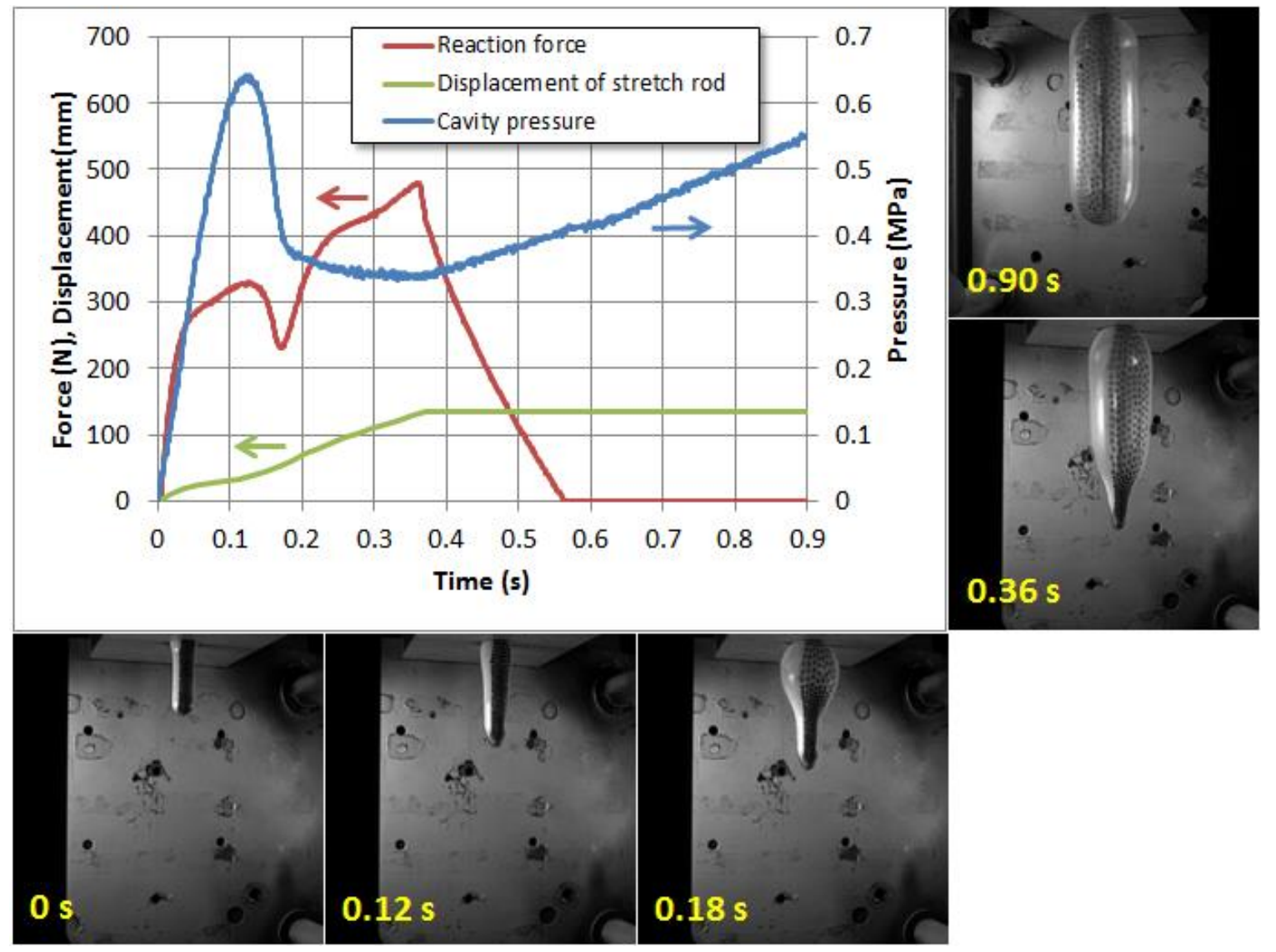

Figure $1 \mathrm{~A}$ typical measurement via the instrumented stretch rod and the corresponding high speed images from one FSB test 
A stereoscopic analysis was employed for the FSB experiments utilising two Photron Fastcam SA1.1 high speed cameras with a resolution of $1024 \times 1024$ pixels at a frame rate of up to $2000 \mathrm{fps}$ and lighting was provided by two LED panels. A customized speckle pattern was designed by Nixon et al. [19] with the average speckle size of $2 \mathrm{~mm}$ to cope with the large deformation of the material during the FSB test. The resolution of each speckle is around $7 \times 7$ pixels, giving a good size for the image correlation software to track its deformation. The image correlation software used for the FSB tests was VIC3D, supplied by Correlated Solutions. Figure 2 (a) illustrates the selection of area of interest (AOI), a subset size of $29 \times 29$ pixels, and a step size of 1 . Figure 2 (b) shows hoop strain via DIC analysis of a blown bottle, and (c) shows the plot of Hencky strains in the axial and hoop directions versus time of one point on the bottle surface. 

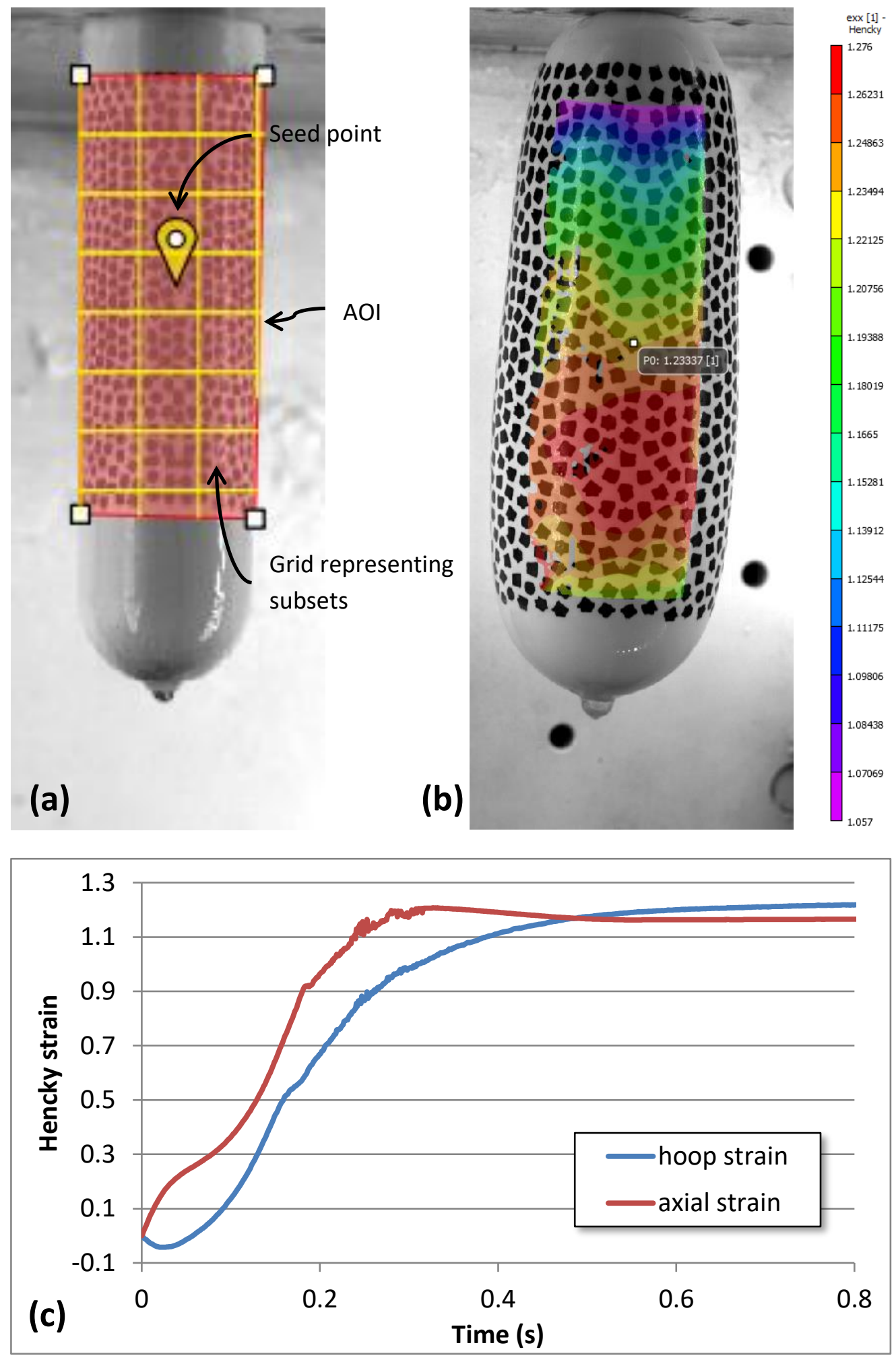

Figure 2 (a) The layout of selected AOI, subset and the seed point; (b) An output of Vic3D, the contour representing the Hencky strain in the hoop direction; (c) and the strain history of one point on the bottle surface 
The preform used throughout the analysis was $31.7 \mathrm{~g}$ with a through diameter of $24.31 \mathrm{~mm}$, a thickness of $4.2 \mathrm{~mm}$ and a length of $97.16 \mathrm{~mm}$. The preforms were injected moulded using PET resin with an intrinsic viscosity of $0.81 \mathrm{dL} / \mathrm{g}$. The same resin was also used to extrude PET sheet with a thickness of $0.5 \mathrm{~mm}$. This extruded PET sheet was then cut into $76 \times 76 \mathrm{~mm}$ square specimens for the biaxial stretching tests.

\section{A novel methodology of obtaining the constitutive behaviour of PET during the free stretch-blow process}

A new characterization method to determine the constitutive behaviour of PET directly from the preform was developed by taking advantage of the data acquisition system [20] together with the DIC system. Taking assumptions such as regarding the evolution of the preform in the free stretch-blow test as an axisymmetric deformation and regarding the stress in the preform as membrane stress, the stress can be determined depending on the geometry of the deforming preform and the measured process parameters.

The geometry of the deforming preform being axisymmetric is one of the premises of this characterization method, therefore, eliminating the rigid body motion from coordinates of the deforming preform is an essential step. The detailed procedure can be found in section 3.1, where the coordinates were constructed by using the strain data obtained from the DIC analysis which didn't include the rigid body motion.

One of the purposes of using strain data obtained from the DIC analysis is to validate finite element simulation of the free stretch-blow process. This FE simulation was constructed using ABAQUS/Explicit coding and an appropriate viscoelastic material subroutine [21,22]. As the DIC analyses local deformations on the exterior layer of the preform while the shell element in ABAQUS/Explicit has an average strain representative of the middle layer, a conversion of coordinates and strains of the preform from the exterior layer to the middle layer needs to be carried out. In section 3.2, this procedure will be demonstrated. In section 3.3, the procedure of calculating the stress in the deforming preform during the free stretch-blow process will be shown. The stress is assumed to be the membrane stress i.e. uniform stress distribution through thickness. The rationality of this assumption will be examined in section $\mathbf{3 . 4}$ by comparing to the thick shell theory where the stress distribution through thickness is considered.

In section 3.5, the stress-strain results generated using this new technique will be validated with the data generated from a biaxial stretching testing machine programmed with similar 
thermal and strain history as that of an element within the preform. Finally, in section 4 results will be compared to show the effects of different process conditions.

\subsection{Elimination of the rigid body motion from the original DIC data}

In the free stretch-blow process, rigid body motion may take place in the case that the preform blows quickly and the tip of preform leaves the stretch rod. Since strains exclude rigid body motion and only contain deformation, it is necessary to use strains from Vic3D to obtain coordinates that don't have the effect of rigid body motion. After this procedure, the coordinates will satisfy one of the premises of calculating the stress in the preform during the free stretch-blow process, i.e. axisymmetric geometry of a deforming preform.

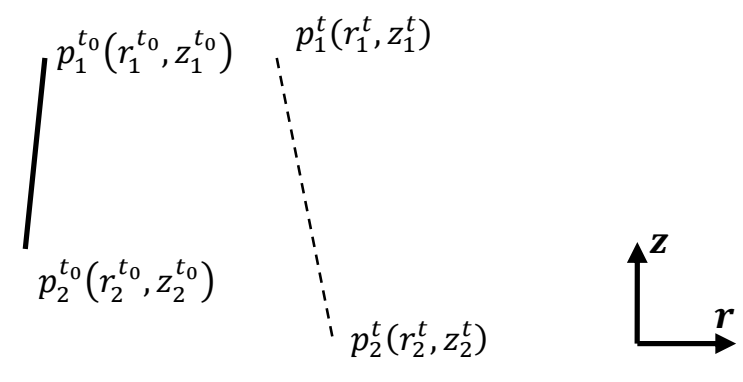

Figure 3 Illustration of an axisymmetric element with its coordinates before and after deforming represented by the solid and dashed lines respectively

Figure 3 illustrated one axisymmetric element before and after deformation. The element consists of two nodes, $p_{1}$ and $p_{2}$, whose cylindrical coordinates are $\left(r_{1}, z_{1}\right)$ and $\left(r_{2}, z_{2}\right)$ respectively. The true axial strain $\left(\varepsilon_{\text {axial }}\right)$ and the true hoop strain $\left(\varepsilon_{\text {hoop }}\right)$ at time $t$ can be expressed by Eqn. (1)

$$
\begin{aligned}
& \varepsilon_{\text {axial }}=\ln \left(\frac{\sqrt{\left(r_{2}^{t}-r_{1}^{t}\right)^{2}+\left(z_{2}^{t}-z_{1}^{t}\right)^{2}}}{\sqrt{\left(r_{2}^{t_{0}}-r_{1}^{t_{0}}\right)^{2}+\left(z_{2}^{t_{0}}-z_{1}^{t_{0}}\right)^{2}}}\right) \\
& \varepsilon_{\text {hoop }}=\ln \left(\frac{r_{1}^{t}+r_{2}^{t}}{r_{1}^{t_{0}}+r_{2}^{t_{0}}}\right)
\end{aligned}
$$

A new set of coordinates on the exterior layer of preform which eliminates the rigid body motion can be reconstructed by using the initial coordinates ( $r$ and $z$ ) and the strain data $\left(\varepsilon_{\text {axial }}\right.$ and $\left.\varepsilon_{\text {hoop }}\right)$. A loop is created to scan through all the nodes at every time increment. When the time equals zero, the initial coordinates of the preform are duplicated. Afterwards, 
the coordinates of two nodes of each stretched element need to be updated by using Eqn. (1) with the given strain data. However, it is not possible to solve for 4 unknown variables $\left(r_{1}^{\mathrm{t}}, z_{1}^{\mathrm{t}}, r_{2}^{\mathrm{t}}\right.$, and $z_{2}^{\mathrm{t}}$ in Figure 3$)$ by two equations. The solution is to use the coordinates of the first node $\left(r_{1}^{\mathrm{t}}, z_{1}^{\mathrm{t}}\right)$ from Vic3D. This node is located at the neck of the preform, which is assumed to not deform. In this way, the rest of the coordinates can be calculated sequentially.

Figure 4 compares the reconstructed coordinates of the exterior layer of perform minus the tip with those directly exported form Vic3D during one free stretch-blow test. At the first three time points, the two layers were identical, suggesting there was no rigid body motion, resulting from the stretch rod stretching the preform up until that point. After that, rigid body motion occurs when the material leaves the stretch rod and the difference in the coordinates appear between the two layers.

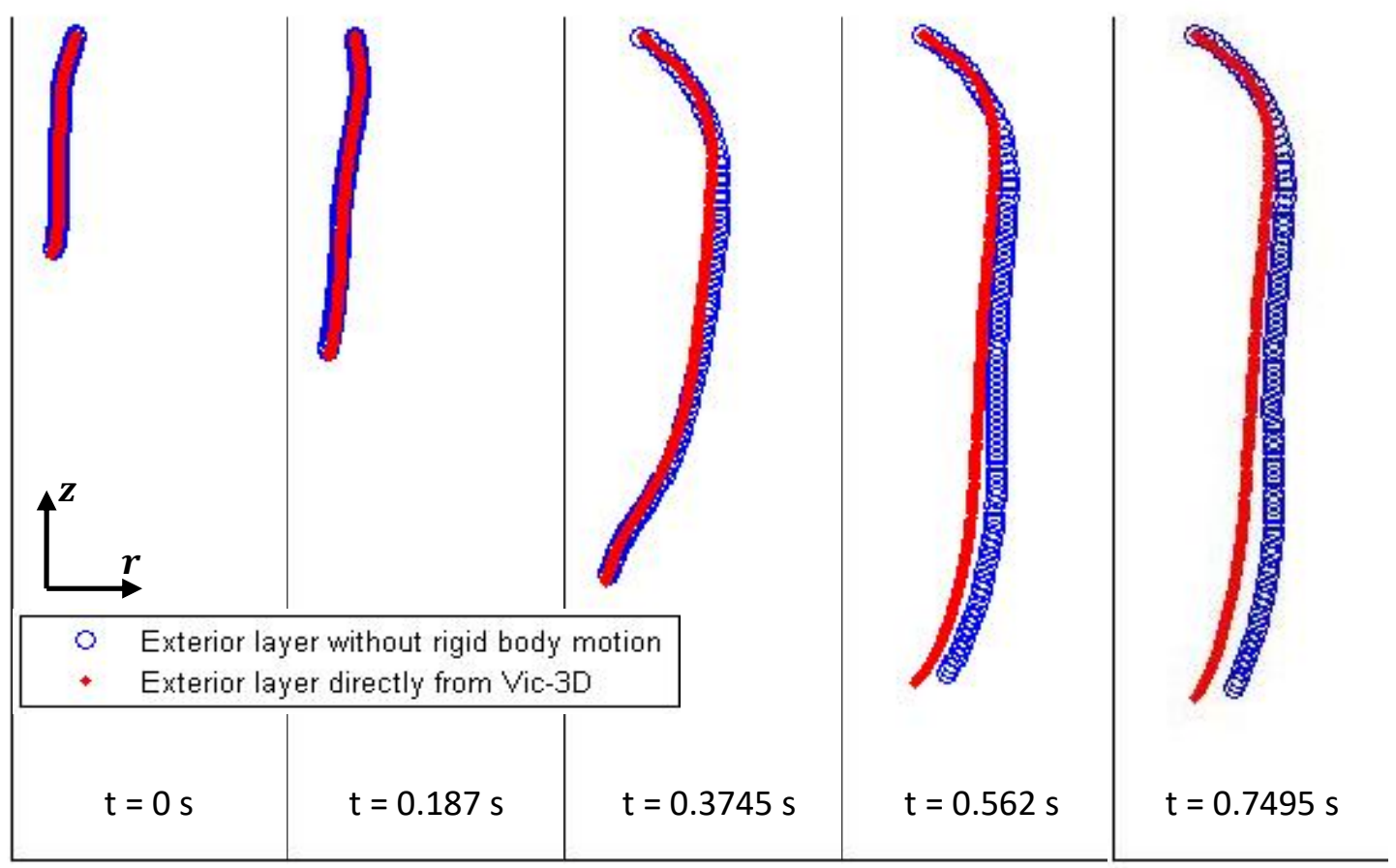

Figure 4 Comparing the coordinates of exterior layer of perform without the rigid body motion (blue open dots) to those exported from Vic3D (red dots)

\subsection{Construction of the middle layer of a deforming preform}

An undeformed preform has a relatively thick sidewall compared to that of a bottle, therefore, the difference in strain through the thickness is not negligible. The strain on the exterior surface of the preform is always less than that on the inner surface. However, this strain difference is not considered for the shell element in ABAQUS/Explicit which has an average 
strain representative of the middle layer. For comparison of strain from DIC and simulation, it's necessary to calculate the experimental strain at the middle layer. The models used for finite element analysis, such as preforms in free stretch-blow simulation and square specimens in biaxial stretching simulation, were constructed on the middle layer of their geometry and so were the outputs. As a result, the middle layer of a deforming preform needs to be derived based on the outputs of DIC analysis.

Two assumptions were made in this method:

1. Axisymmetric elements of the preform are divided horizontally, i.e. the z-coordinates of the corresponding nodes are identical on the middle layer and exterior layer respectively, as shown in Figure 5.

2. The material is incompressible, i.e. the elemental volume is constant.

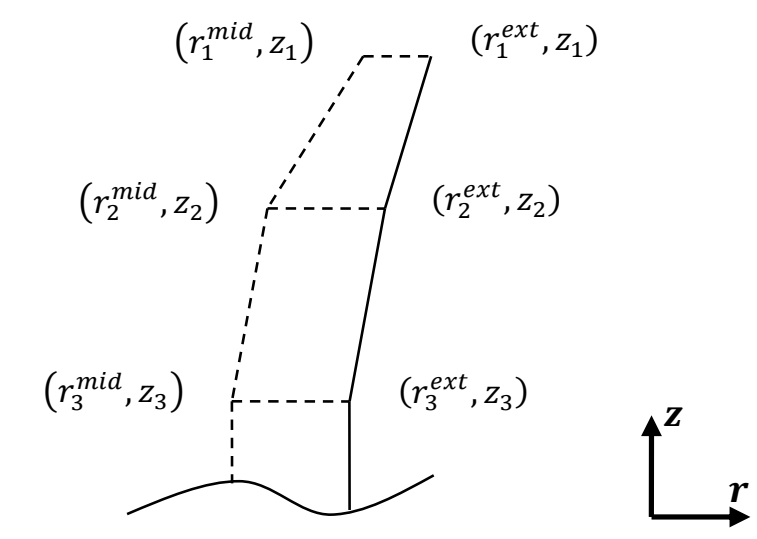

Figure 5 Illustration of the axisymmetric nodes on exterior and middle layers of the preform

Figure 5 illustrates the coordinates of three nodes on the exterior surface of the preform and those related nodes on the middle layer which need to be constructed. As the initial thickness of the preform is known, the coordinates of the nodes on the middle layer can be easily calculated when time equals zero by Eqn. (2).

$$
\begin{aligned}
& r^{\text {mid }}=r^{\text {ext }}-\frac{\text { thickness } / 2}{\sin (\operatorname{atan}(k))} \\
& z^{\text {mid }}=z^{\text {ext }}
\end{aligned}
$$

where $\mathrm{k}$ is the gradient of the element on the exterior surface. After the coordinates of the middle layer of the undeformed preform are obtained, half of the volume of each element can be calculated. One axisymmetric element shown in Figure $\mathbf{5}$ can be regarded as a 
hollow conic frustum. The volume of conic frustum can be calculated by Eqn. (3), where $\mathrm{h}$ is the height of the frustum, and $r \& R$ are the radii of the upper and lower bases, respectively.

$$
\text { Volume }=\frac{1}{3} \pi h\left(r^{2}+r R+R^{2}\right)
$$

Applying this to the preform, the element volume is the difference in the volume of two frustums constructed by exterior coordinates and middle coordinates respectively, as expressed in Eqn. (4).

$$
\begin{aligned}
& V^{\text {ext }}=\frac{1}{3} \pi\left(z_{j+1}-z_{j}\right)\left(\left(r_{j}^{\text {ext }}\right)^{2}+r_{j}^{\text {ext }} \cdot r_{j+1}^{\text {ext }}+\left(r_{j+1}^{\text {ext }}\right)^{2}\right) \\
& V^{\text {mid }}=\frac{1}{3} \pi\left(z_{j+1}-z_{j}\right)\left(\left(r_{j}^{\text {mid }}\right)^{2}+r_{j}^{\text {mid }} \cdot r_{j+1}^{\text {mid }}+\left(r_{j+1}^{\text {mid }}\right)^{2}\right) \\
& V_{\text {element }}=V^{\text {ext }}-V^{\text {mid }}
\end{aligned}
$$

For the deformed preform i.e. time $>0$, the radius of the first node on the middle layer is guessed initially. Based on this guess value and the elemental volumes obtained previously, the rest of the r-coordinates can be calculated sequentially based on Eqn. (4) by assuming the incompressibility of the material. The position of the first node influences the position of the rest of the nodes significantly. For instance, Figure 6 shows two different guessed first nodes ( $r_{1}^{\text {mid }}$ guess 1 and $r_{1}^{\text {mid }}$ guess 2 ). It is obvious that once the initial guess value is correct, the predicted nodal coordinates on the middle layer follow the profile of the exterior layer which is what one would expect (in the case of guess 1 ). In the case of guess2, in order to meet the requirement of constant volume of each element, there is a big deviation between the predicted nodal coordinates and a zig-zag profile is obtained which is not realistic. The difference between guess 1 and guess 2 can be distinguished by comparing the gradient of each element between the middle and the exterior layers. An optimization for the $r$-coordinate of the first node is then carried out to minimize the sum of the gradient difference of all the elements. The function fsolve() in MATLAB ${ }^{\circledR}$ was used to execute this optimization. The procedure of predicting the coordinate of the middle layer is shown in Figure 7. 


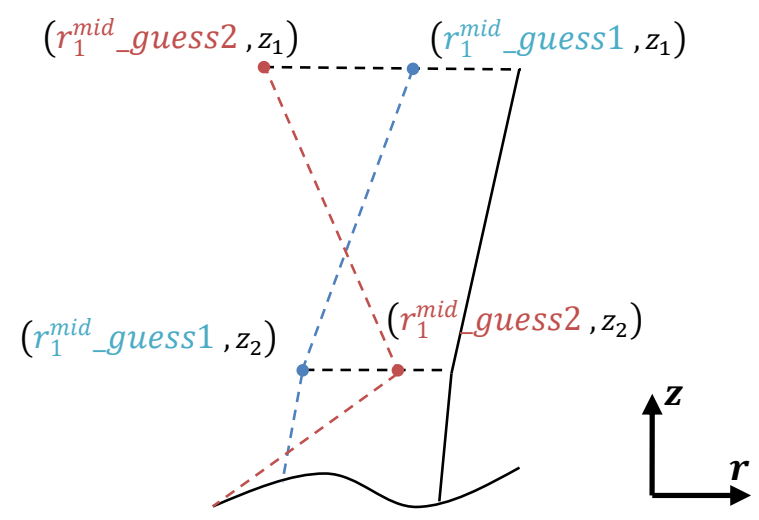

Figure 6 Illustration of the axisymmetric nodal prediction based on the different guessed first nodes 


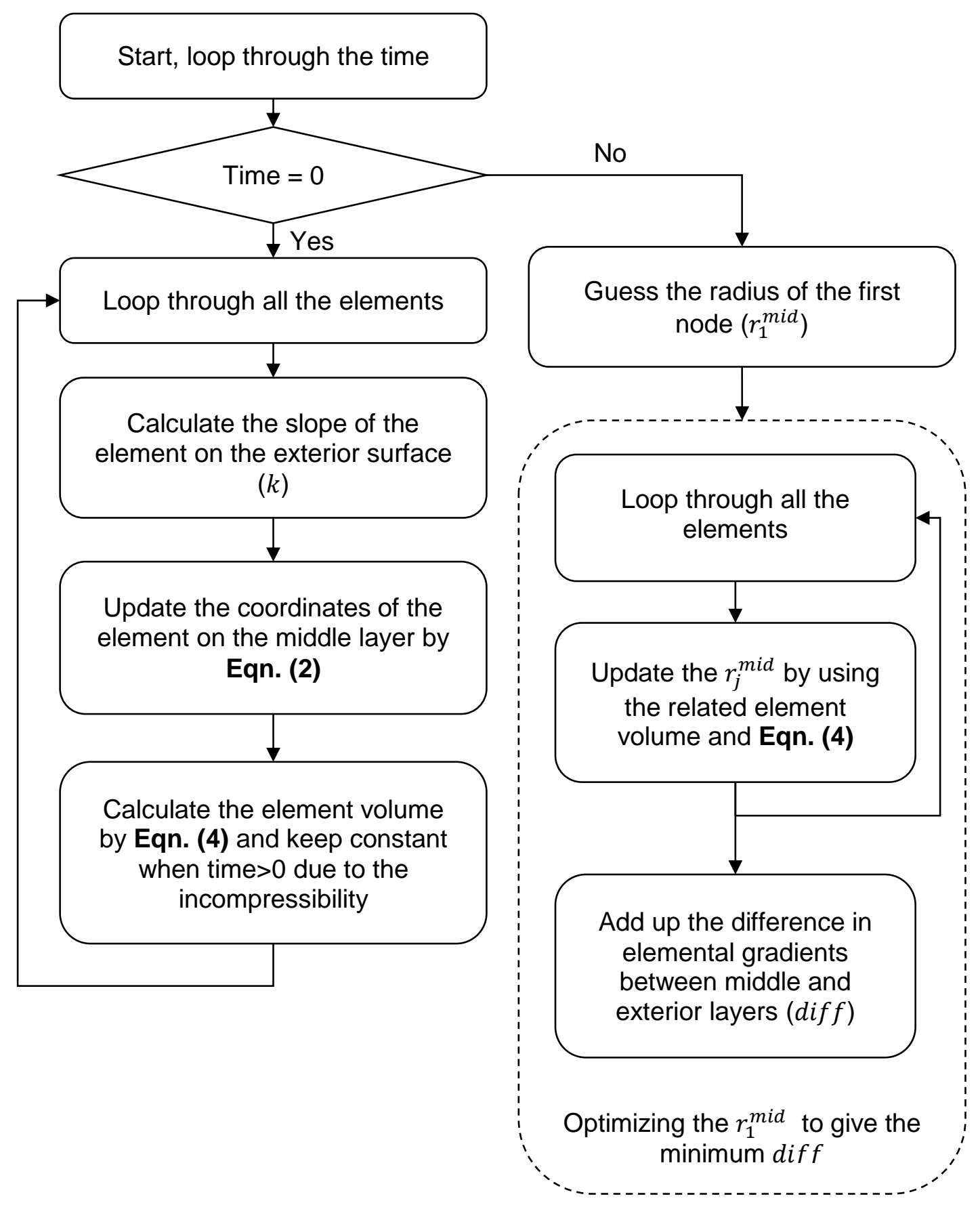

Figure 7 Flow chart demonstrating the method of reconstructing the coordinates on the middle layer of the preform

The evolving geometry of both layers of a preform during blowing is shown in Figure 8 (a), where the blue solid line represents the exterior layer of the preform and the red dash line represents its middle layer. Figure $\mathbf{8}$ (b) demonstrates the strain comparison of one element of this preform. One can see that the axial strains on the middle and exterior layers are identical, but the hoop strain on the middle layer is much higher than that of the exterior layer (2.997 versus 2.302). 


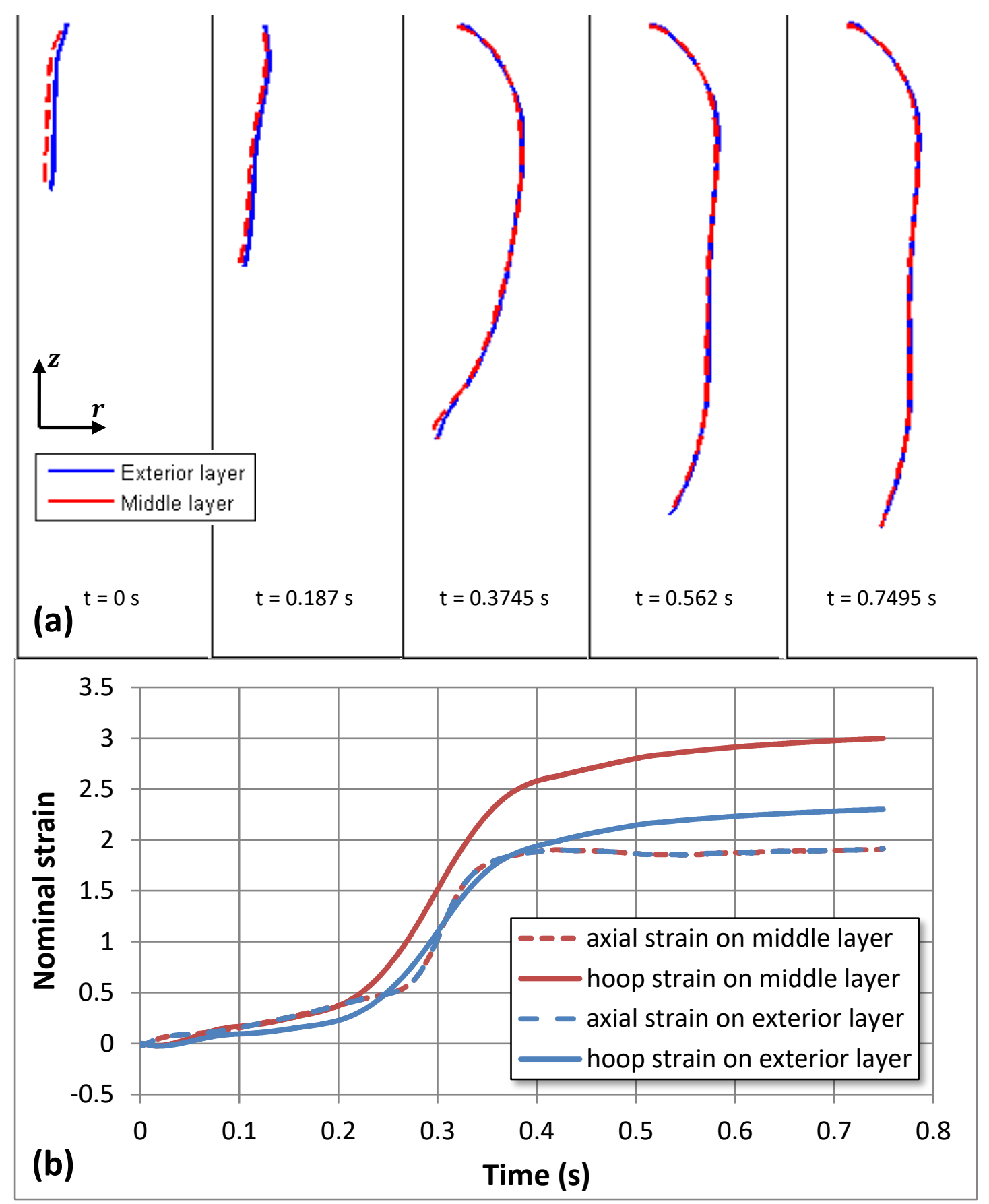

Figure 8 (a) Evolving geometry of exterior and middle layers of a preform during a free stretchblow test; (b) strain comparison of one element on the sidewall between these two layers

\subsection{Determination of the stress response of a deforming preform}

A blowing preform driven by pressurised air can be treated as an axisymmetric shell with internal pressure. For any element of the shell, there is a 3D stress system, i.e. the stresses in two principal orthogonal directions tangential to the surface geometry and the stress through the thickness Eqn. (5). If the wall thickness is less than about one-tenth of the 
principal radii of curvature of the shell, the stress through the thickness may be neglected and the shell acts as a membrane which does not provide bending resistance [23].

$$
\frac{\sigma_{\text {hoop }}}{R_{1}}+\frac{\sigma_{\text {axial }}}{R_{2}}=\frac{p}{t}
$$

where $\sigma_{\text {hoop }}$ is the tensile stress along a parallel circle, $\sigma_{\text {axial }}$ is the tensile stress in meridional direction, $R_{1}$ is the radius of curvature in hoop direction and $R_{2}$ is the meridional radius of curvature. $t$ and $p$ represent the thickness and internal pressure respectively. Therefore, Eqn. (5) can be used to calculate the membrane stresses depending on the geometry of the blowing preform. Figure 9 (a) illustrates curvature radii of one element of the blowing preform. The radius of curvature in the hoop direction $\left(R_{1}\right)$ can be further expressed by using the radius of the horizontal circle $(r)$ as shown in Eqn. (6)

$$
R_{1}=\frac{r}{\sin \theta}
$$
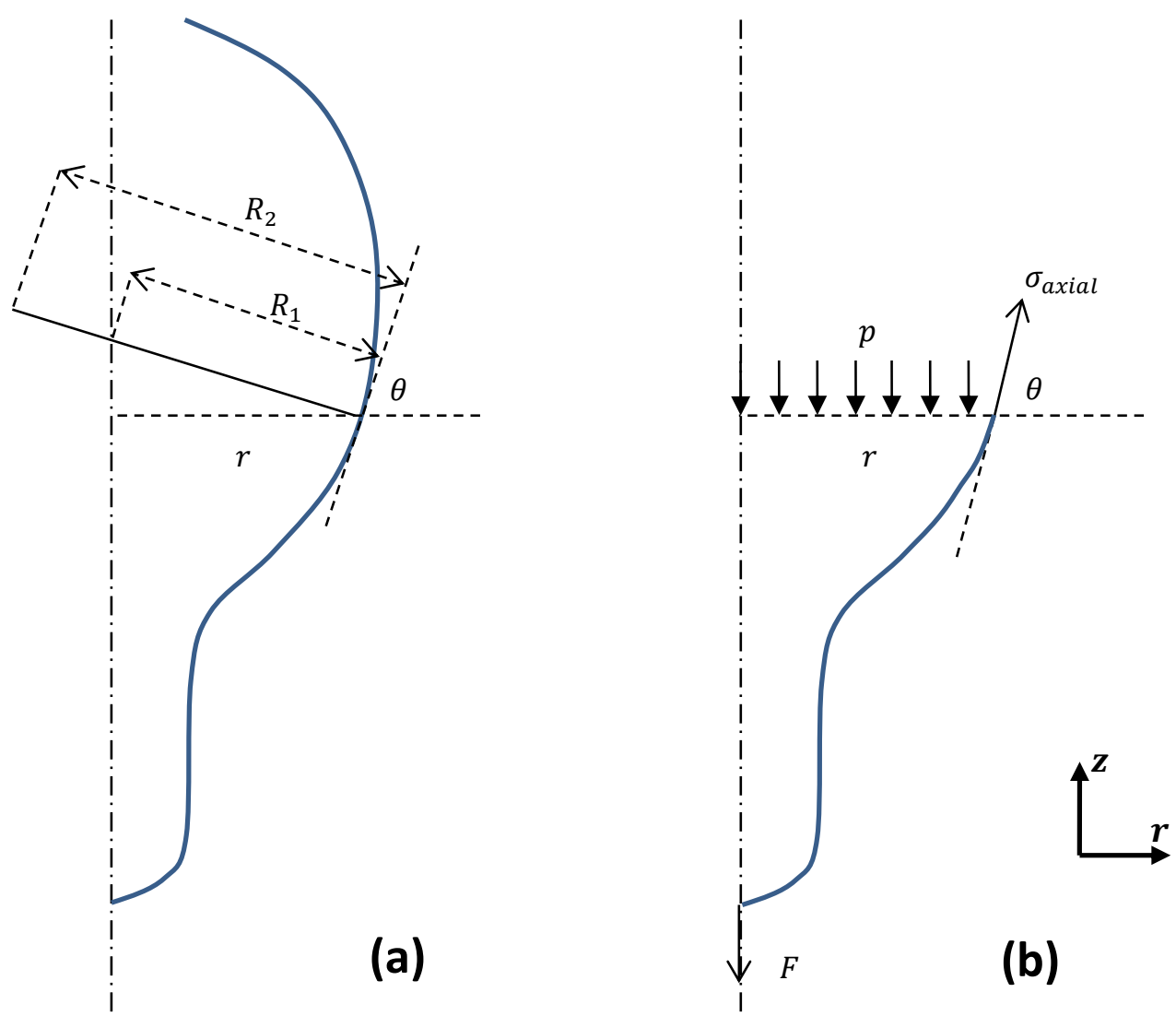

Figure 9 (a) Illustration of the curvature radii of one axisymmetric element of the blowing preform, and (b) axisymmetric sketch of the free body diagram for one element of the blowing preform 
In order to solve Eqn. (5) which contains two unknown variables $\left(\sigma_{\text {axial }}\right.$ and $\left.\sigma_{\text {hoop}}\right)$, another equilibrium equation should be introduced. As a result, a free body diagram is applied to solve the axial stress. From Figure 9 (b), one equilibrium relationship can be found and expressed by Eqn. (7)

$$
\sin \theta \sigma_{\text {axial }} 2 \pi r t=\pi r^{2} p+F
$$

where $p$ is the internal pressure and $F$ is the reaction force at the tip of the stretch rod.

After rearranging Eqns. (5) - (7) the membrane stresses of any element on the preform in both the axial and hoop directions can be expressed in Eqn. (8)

$$
\begin{gathered}
\sigma_{\text {axial }}=\frac{1}{2 t \sin \theta}\left(r p+\frac{F}{\pi r}\right) \\
\sigma_{\text {hoop }}=\frac{r}{\sin \theta}\left(\frac{p}{t}-\frac{\sigma_{\text {axial }}}{R_{2}}\right)
\end{gathered}
$$

An additional procedure is required for calculating the radius of curvature $\left(R_{2}\right)$ through the axial direction. Fitting the geometry profile of the preform shown in Figure 9 (a) by using a cubic polynomial, the radius of curvature at a certain position is calculated by using Eqn. (9) [24].

$$
R_{2}(z)=\left|\frac{\left(1+r^{\prime}(z)^{2}\right)^{1.5}}{r^{\prime \prime}(z)}\right|
$$

\subsection{Evaluation of the stress using thick-wall theory}

In most cases during the blowing deformation, a preform can be treated as a thin-wall container, hence, the stress in the preform can be calculated assuming membrane theory. However, at beginning of the deformation thickness to radius ratio of the preform is typically in the range 0.3 to 0.4 where thick wall theory is more appropriate. In this section, the maximum and minimum stresses predicted by thick wall theory are compared to evaluate if the bending effect is significant.

The straight part of an undeformed preform can be regarded as a thick wall cylinder, and its stress distribution through thickness can be expressed by Eqn. 10 [25]. 


$$
\sigma_{\text {hoop }}=\frac{p R_{1}^{2}}{R_{2}^{2}-R_{1}^{2}}\left(1+\frac{R_{2}^{2}}{r^{2}}\right)
$$

where $p$ is the internal pressure, $R_{1}$ and $R_{2}$ are the internal and external radii respectively, $r$ is the radius between $R_{1}$ and $R_{2}$. The hoop stress reaches a maximum value when $r=R_{1}$, and a minimum value when $r=R_{2}$.

One element on the preform is selected to calculate its hoop stress via Eqn. 10 during the free stretch-blow process. The position of this element is in the middle of the straight wall of the preform which is close to the cylindrical scenario. An approximation has been made during the rapid inflation phase $(0.15 s-0.26 s)$ when the element is not vertical. Once the bottle starts to form (after $0.26 \mathrm{~s}$ ), the selected element is cylindrical again.

Figure 10(a) shows the external and internal radii of this element as well as the measured cavity pressure. Figure 10(b) reveals the maximum and minimum hoop stresses through the thickness of this element during the deformation and the difference between them. One can see that there is no significant difference in the stresses, i.e. with a value less than $0.6 \mathrm{MPa}$. Therefore, it's adequate to ignore the bending effect and to assume a uniform stress distribution through the thickness of a preform during the whole free stretch-blow process. 


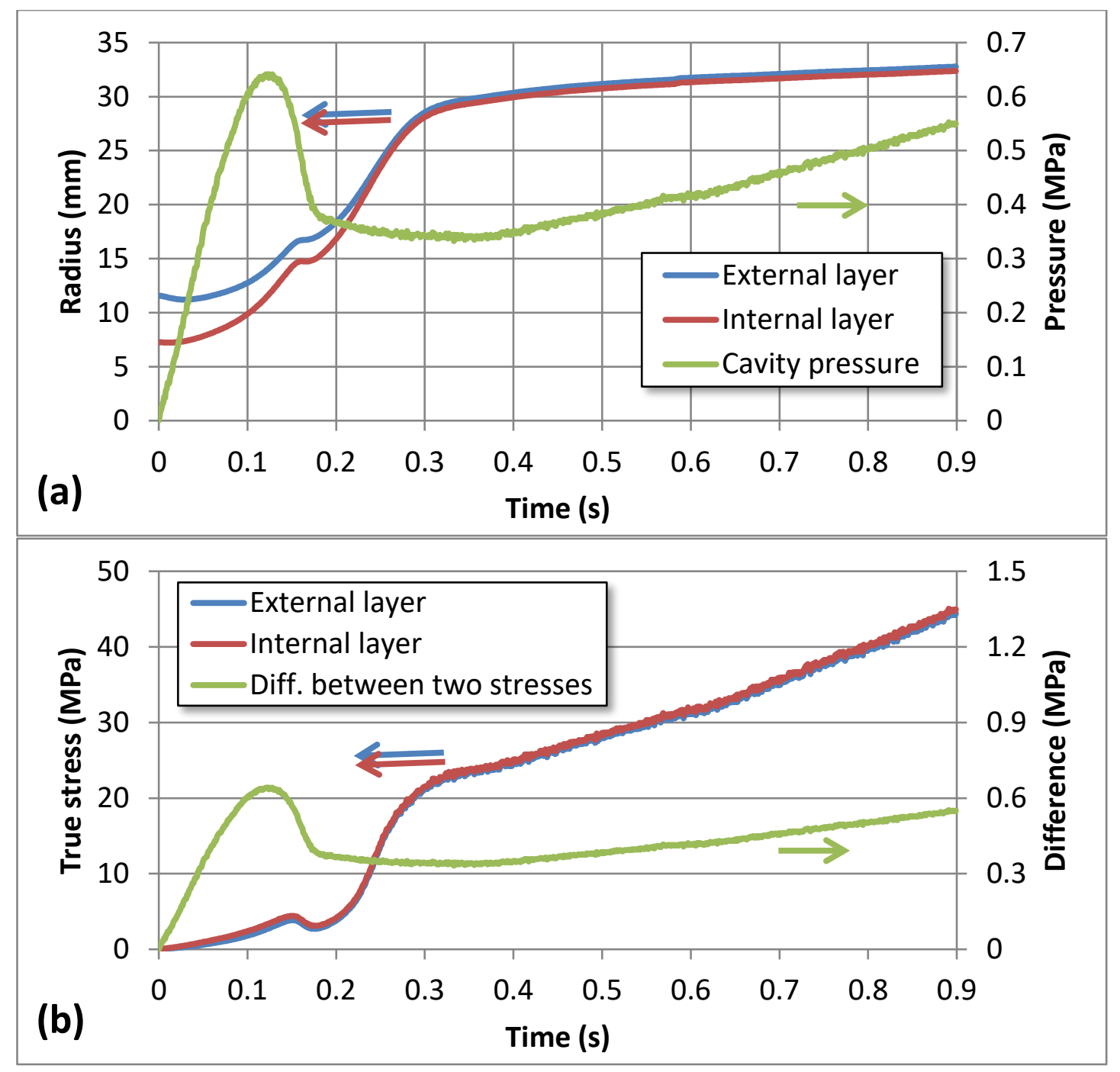

Figure 10 demonstrates the stress calculation when thick wall cylinder was applied. (a) shows the necessary inputs obtained from a free stretch-blow test, and (b) shows the calculated stresses on two layers and the difference between them

\subsection{Validation of the new method by comparing the stress-strain data from the biaxial stretching testing machine}

In order to obtain a level of validation of the methodology, the strain versus time curve measured by the DIC was replicated by the biaxial stretching testing machine in QUB [26] with the object of comparing the stress-strain curve measured from the blowing preform to that from the biaxial stretcher.

An element located on the same position on the preform (30 $\mathrm{mm}$ from the neck support ring) was selected for two free stretch-blow tests with different conditions. One test was carried out at low temperature and low mass flow rate, resulting in an average strain rate of $10 / \mathrm{s}$ in the axial direction and $7 / \mathrm{s}$ in the hoop direction, and is referred as 'slow test'. Another one is 
called 'fast test', which was done at high temperature and high mass flow rate, where the average strain rate was $47 / \mathrm{s}$ in both directions. The corresponding biaxial stretching tests were carried out by using the strain history observed by the DIC analysis and at the temperature of blowing. The comparison between the strain history from the DIC analysis and the biaxial stretching test is plotted in Figure $\mathbf{1 1}$ (a) and (c), presented by the solid and dotted lines respectively.

It can be seen that in the 'slow test', the biaxial stretching testing machine was able to capture almost all the strain history in the blowing process except the reduction in axial strain after 0.6 seconds, whilst in the 'fast test', the machine cannot meet the deformation speed of the material during blowing due to its physical limitation. The above findings reflect the two physical limitation of the machine:

1) The clamps of either direction cannot move backwards.

2) The maximum speed of motion cannot exceed $1 \mathrm{~m} / \mathrm{s}$ which is equivalent to a nominal strain rate of $32 / \mathrm{s}$.

Figure 11 (b) and (d) show the comparisons of the corresponding stress-time curves calculated directly from the preform and from the biaxial stretcher for the 'slow test' and 'fast test' respectively. In the 'slow test', the curves have good agreement between the two methods as the biaxial stretching testing machine can fully capture the strain history in this case as shown in Figure 11 (b). In the hoop direction, the two red curves have a similar gradient at the strain hardening region. There is an offset of around $7 \mathrm{MPa}$ after 0.5 second which is probably due to the difference in the axial strains. In addition, its $R^{2}$ value of 0.93 was calculated in order to evaluate the difference between these red curves. In the axial direction, the stress data from the calculation and the machine match each other very well, with a $R^{2}$ value of 0.97 .

On the other hand, the stress-time curves of the 'fast test' does not compare as favourably as the 'slow test'. By comparing the curves in Figure 11 (d), one can see an offset of 16 $\mathrm{MPa}$ in the hoop stresses $\left(\mathrm{R}^{2}\right.$ value of 0.57$)$ and $7 \mathrm{MPa}$ the axial stresses ( $\mathrm{R}^{2}$ value of 0.74$)$. This is mainly due to the high deformation speed which the machine was not able to achieve.

The high strain rates resulted in a significantly higher stress response in the free blow experiments. This therefore highlights one of the major advantages of this technique is that we are now able to obtain stress-strain data at very high rates that are taken directly from a blow moulding process. In summary, this new characterization method is competent for obtaining the constitutive behaviour of PET during the free stretch-blow test. The results 
generated by this method will be compared to show the effects of different process conditions in the following sections.

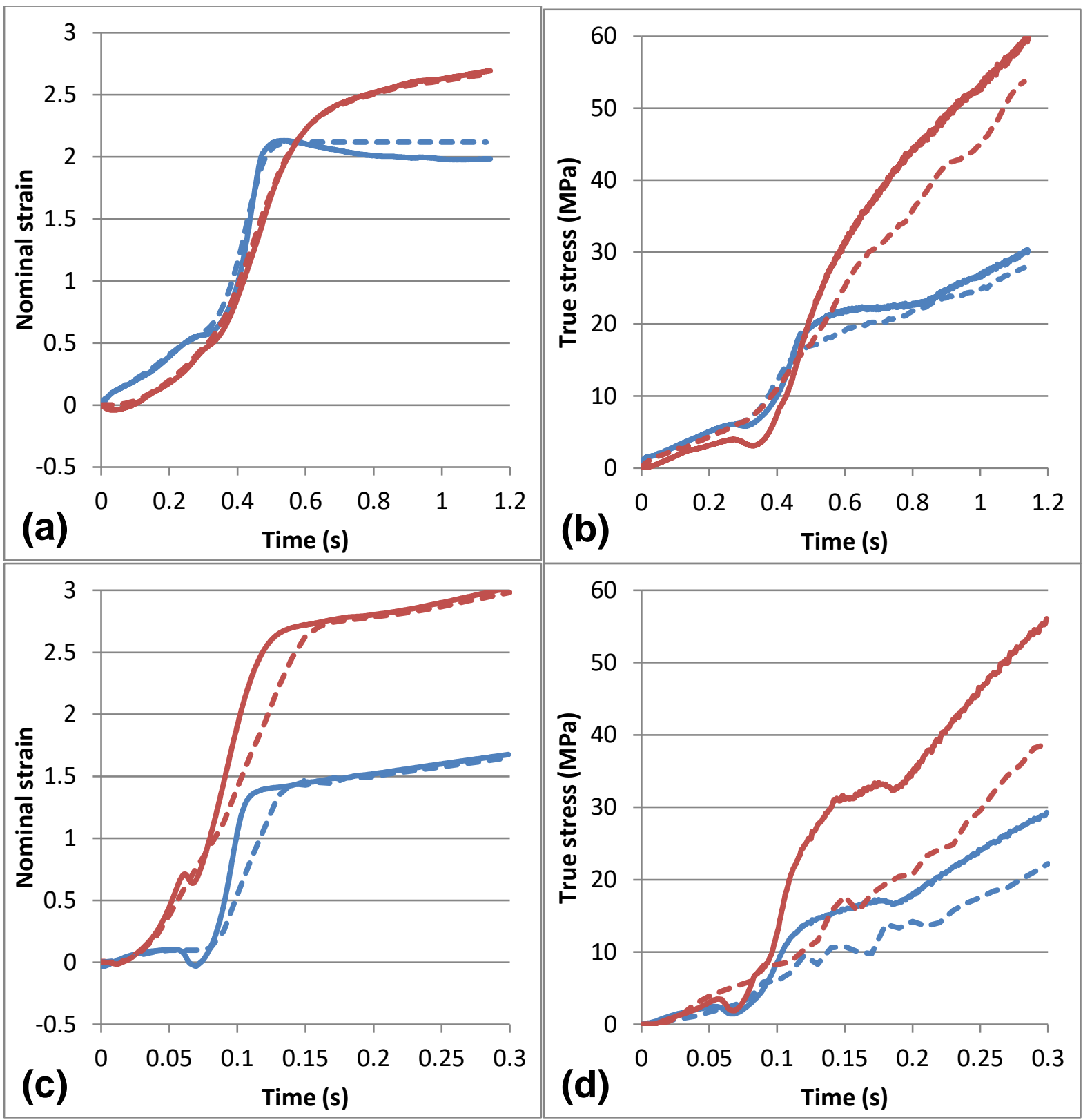

Figure 11 (a) and (c) are the strain comparison between DIC and biaxial stretching testing machine in 'slow' and 'fast' test respectively; (b) and (d) are the corresponding stress comparisons. (The solid lines represent the DIC strain and the calculated stress; the dashed lines represent the strain and stress data from the machine. The blue lines are of the axial direction; the red lines are of the hoop direction.)

\section{Results}

\subsection{Effect of temperature}


The high speed images of free stretch-blow tests where the preforms were heated to temperatures ranging from $95^{\circ} \mathrm{C}$ to $110^{\circ} \mathrm{C}$ and blown under the 'high' mass flow rate $(34 \mathrm{~g} / \mathrm{s})$ are displayed in Figure 12. The effect of the temperature on the blowing behaviour is obvious from these images. The preform heated to $95^{\circ} \mathrm{C}$ took 3 times as longer as that heated to $110^{\circ} \mathrm{C}$ to fully form i.e. reach its natural draw ratio. The dot on the preform $(30 \mathrm{~mm}$ from the neck support ring) indicates the selected element, from which the strain history and stress-strain curves were extracted, as shown in Figure 13.

The strain history of the selected element in Figure 13 (a) shows the same trend as the images, where the material deformed earlier and faster with the higher temperature. For instance, the maximum strain rate of the material at $110^{\circ} \mathrm{C}$ was $49 / \mathrm{s}$ in the axial direction and $35 / \mathrm{s}$ in the hoop direction. While the maximum strain rate of the material heated at $95^{\circ} \mathrm{C}$ was $24 / \mathrm{s}$ in the axial direction and $18 / \mathrm{s}$ in the hoop direction. Moreover, the difference in the blowing time was 0.03 second between $100^{\circ} \mathrm{C} / 105^{\circ} \mathrm{C}$ and $105^{\circ} \mathrm{C} / 110^{\circ} \mathrm{C}$. However, there was a delay of the blowing in the test whose heating temperature was $95^{\circ} \mathrm{C}, 0.15$ seconds later than that heated at $100^{\circ} \mathrm{C}$. It should be noted that the temperatures shown in the figure are the temperature setting of oil bath. The actual temperature of preform at the beginning of blowing is expected to be 4 to $5^{\circ} \mathrm{C}$ lower than the setting value due to transportation time from oil bath to blowing station. The time was carefully controlled to be counted at $18 \pm 1$ seconds. Therefore, in the $95^{\circ} \mathrm{C}$ case the temperature of the material was close to $T_{g}$, resulting in more resistance in the material to deform.

From the stress-strain curves in Figure 13 (b), the effect of temperature can be seen. The lower stress response was from the test with the higher heating temperature. However the gradient of the strain hardening region is less diverse when compared with the data typically generated from biaxial stretching tests [9][11], even when comparing a similar temperature range from $91^{\circ} \mathrm{C}$ to $105^{\circ} \mathrm{C}$. The cause of this observation is due to the deformation of the material being driven by the internal pressure during the blowing instead of being controlled by the imposed displacement profile in the biaxial stretching test, i.e. load control versus displacement control. The material with the higher temperature deforms faster, and vice versa. However, these two factors affect the material behaviour during the deformation in opposite ways, i.e. the higher temperature makes the material softer but the higher deformation rate makes the material stiffer [10][12]. Hence, the combination of high temperature and high deformation rate or low temperature and low deformation rate reduces the diversity in the gradient of the strain hardening region. 


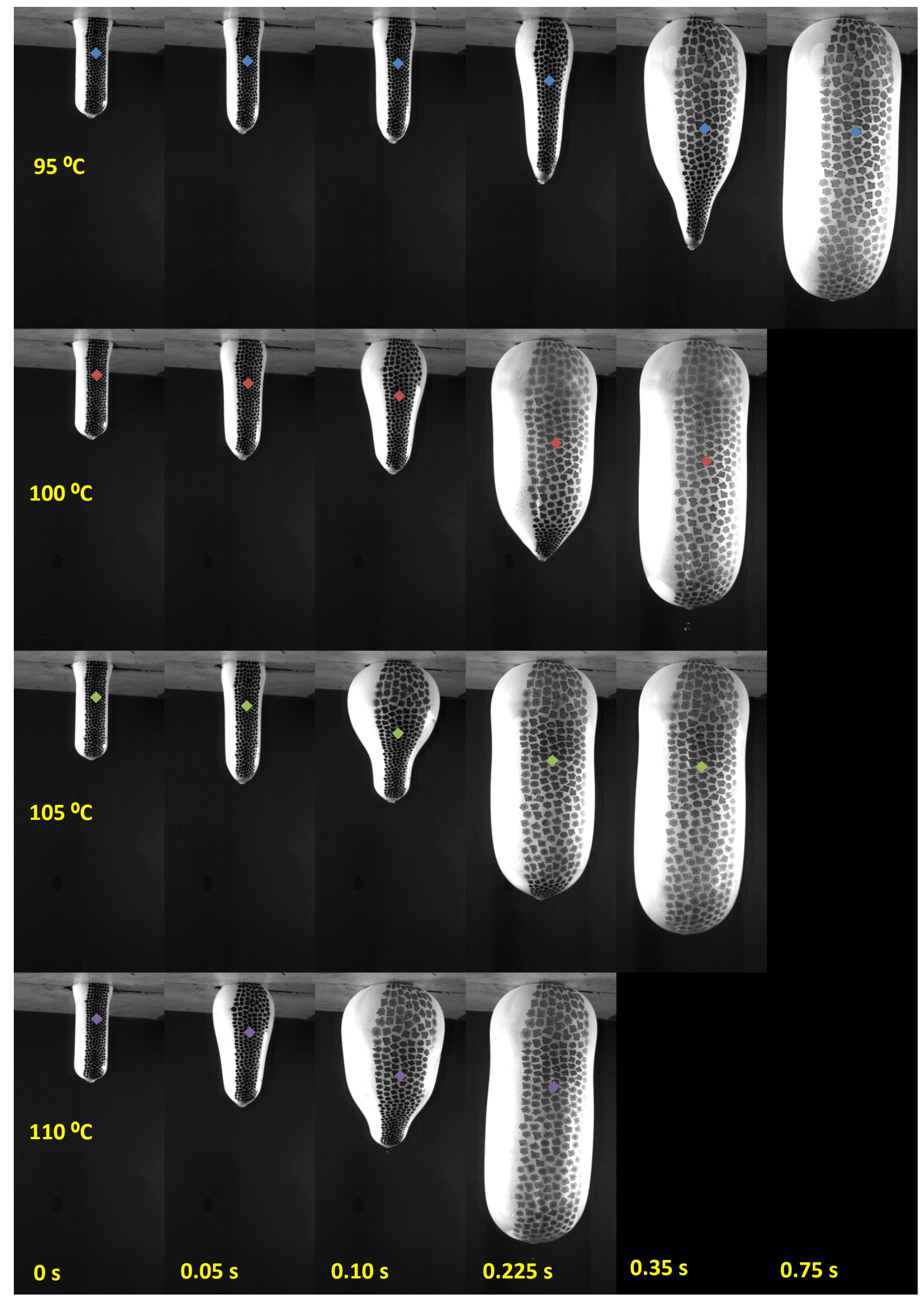

Figure 12 High speed images of free stretch-blow tests to show the effect of different heating temperatures of the preforms. The dot on the preform indicates the point where the DIC data was extracted from. 

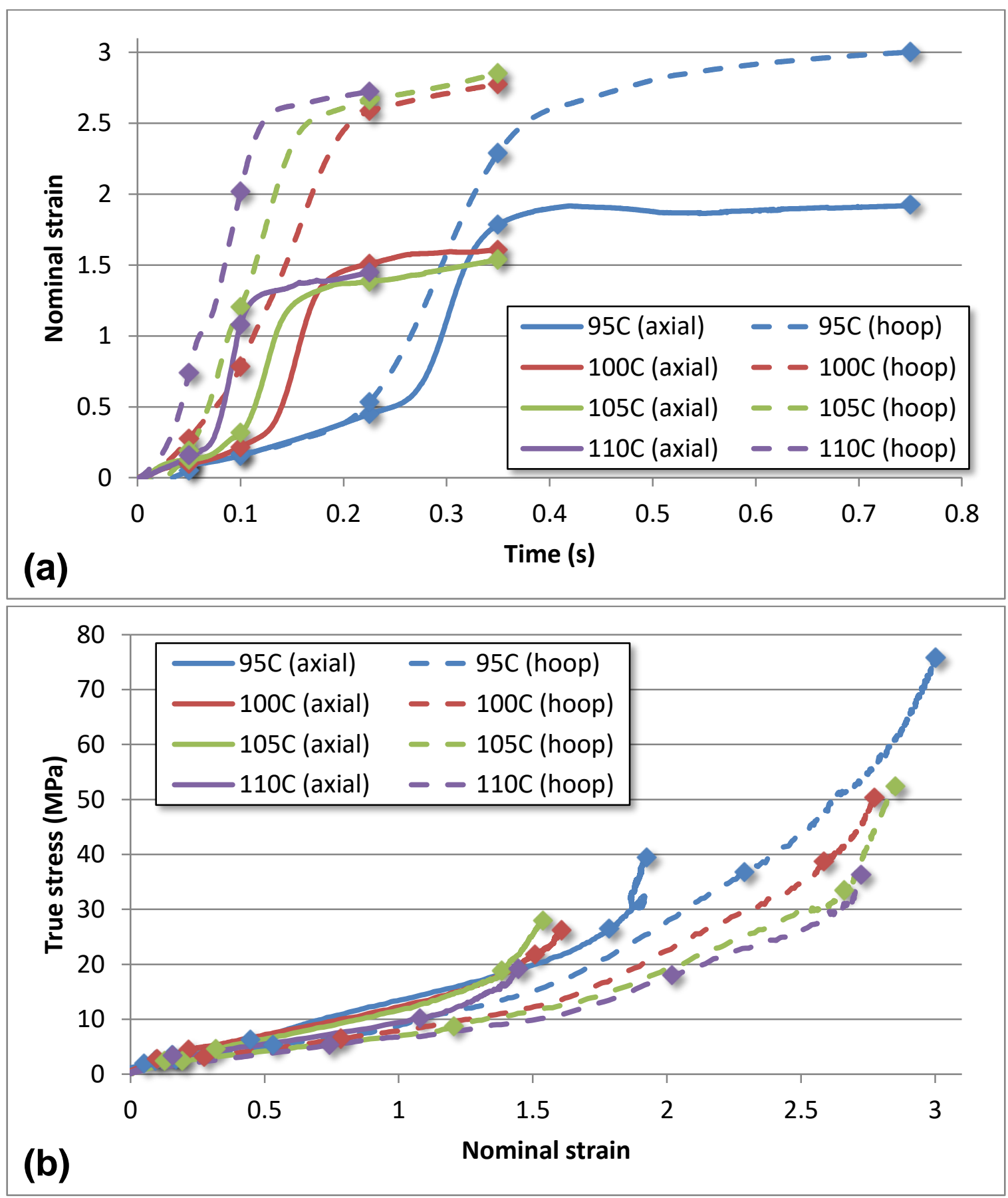

Figure 13 (a) the strain history and (b) the stress-strain curves of free stretch-blow tests as a function of the temperature. The dots on the curves represent the corresponding time to the high speed images. The solid lines are of the axial direction; the dashed lines are of the hoop direction.

\subsection{Effect of the air mass flow rate}


The high speed images of two free stretch-blow tests where the preforms were heated to $95^{\circ} \mathrm{C}$ and blown under different air mass flow rates (9 versus $34 \mathrm{~g} / \mathrm{s}$ ) are displayed in Figure 14. It can be seen that the preform in the 'low MFR' test took 0.3 second more to form a bottle than that in the 'high MFR' test. The dot on the preform (30 mm from the neck support ring) also indicates the selected element, from which the strain history and stress-strain curves were extracted, as shown in Figure 15.

In Figure 15 (a), it can be seen that the different air mass flow rates introduced different strain history. For the 'high MFR' test, the maximum strain rate was $24 / \mathrm{s}$ in the axial direction and 18/s in the hoop direction. While in the 'low MFR' test, the maximum strain rate was 19/s in the axial direction and 10/s in the hoop direction. In addition, the strain history of the "high MFR' test (red lines) reveals that the material deformed in a simultaneous biaxial manner, i.e. the strains in both directions increased proportionally. On the other hand, when the material was deformed under the low mass flow rate, its strain history showed a sequential biaxial deformation taking place, i.e. the deformation in one direction takes place after the deformation completes in another direction. In this case, the axial strain (blue solid line) increased to the nominal strain of 2.2 and stayed at that level while the hoop strain (blue dashed line) was steadily increasing.

The constitutive behaviour due to the different strain history can be easily seen from the comparison of the stress-strain curves, as shown in Figure 15 (b). For the 'high MFR' test (red lines), the gradients in the strain hardening region of the stress-strain curves were similar thanks to the simultaneous deformation mode. The shift between the hoop and axial stresses is due to the inequality in the strains. However, in the 'low MFR' test, the gradient of the strain hardening region started to diversify after a nominal strain of 1.3 , and a stiffer response in the hoop direction can be found afterwards (see the blue lines in Figure 15 (b)). This is believed to be the consequence of the sequential deformation. This phenomena was found by several researchers [5][12] who carried out a series of sequential biaxial stretching tests with different stretch ratios in the first stretching phase. They found that the constitutive behaviour of PET during the second stretching phase is strongly dependent on the stretch ratio achieved in the first stretching stage, especially when the first stretch ratio achieves a nominal strain of 1.5 - 2 . 


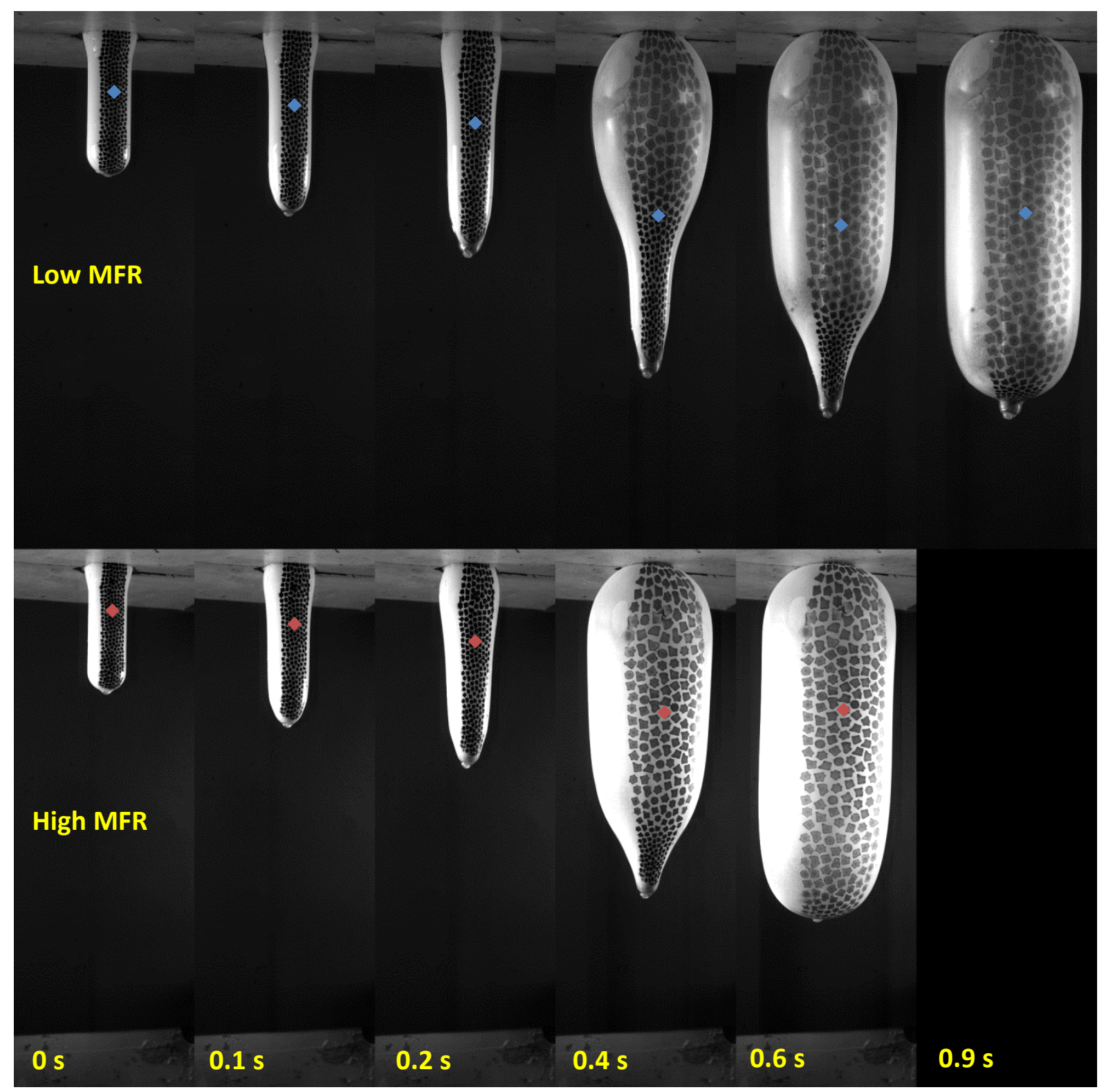

Figure 14 High speed images of free stretch-blow tests under different air mass flow rates. The dot on the preform indicates the point where the DIC data was extracted from. 

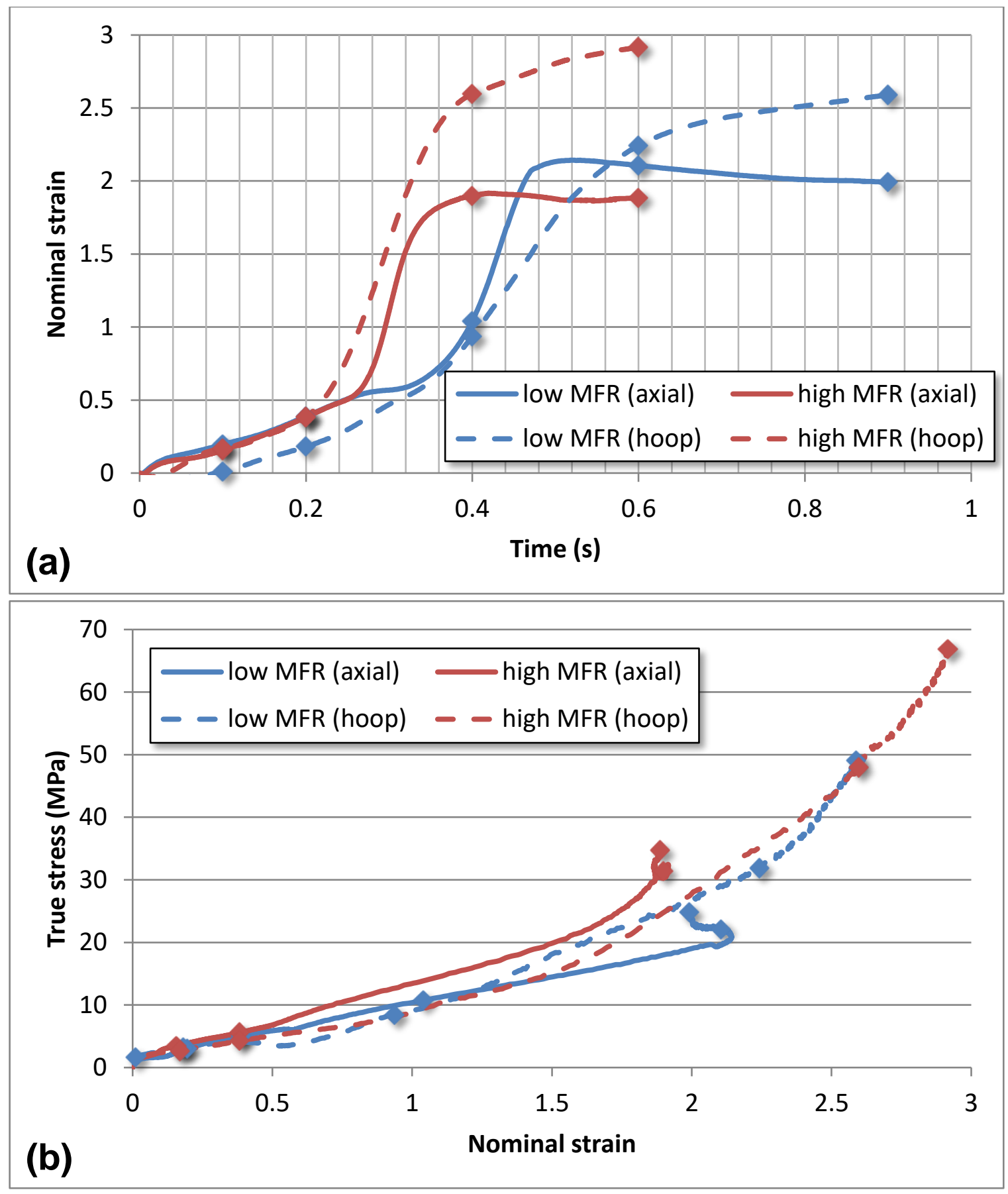

Figure 15 (a) the strain history and (b) the stress-strain curves of free stretch-blow tests as a function of the air mass flow rate. The dots on the curves represent the corresponding time to the high speed images. The solid lines are of the axial direction; the dashed lines are of the hoop direction.

\section{Conclusions}

In this work, a novel, reliable and non-contact characterization method was developed based on a data acquisition system built-in with a stretch rod and a DIC system to determine the 
stress-strain relationship of material in deforming preforms during the free stretch-blow process. This characterization method was validated by using a standard biaxial stretching test with the same strain history.

The effect of heating temperature and air mass flow rate on the deformation behaviour of PET were investigated by analysing its strain history and stress-strain relationship. It was found that in the blowing scenario, the diversity of the gradient in the strain hardening region throughout the tests with different heating temperatures was not as large as that in the biaxial stretching tests, which is due to the combination of the effects from temperature and strain rate. In addition, a sequential deformation was observed in the blowing scenario, especially in the 'low MFR' rate tests which had a significant effect on the stress-strain behaviour.

By using this new characterization method, it is possible to obtain the local stress-strain relationship in a preform during free stretch-blow tests. This method also allows one to characterize the constitutive behaviour of various materials under blow moulding conditions directly from a preform without the need for any biaxial stretching test. 


\section{Reference}

[1] C.W. Tan, G.H. Menary, Y. Salomeia, C.G. Armstrong, M. Picard, N. Billon, et al., Modelling of the Injection Stretch Blow Moulding of PET containers via a Pressure-Volume-time Thermodynamic Relationship, International Journal of Material Forming. (2008) 799-802.

[2] C. Gerlach, C.P. Buckley, D.P. Jones, Development of an Integrated Approach to Modelling of Polymer Film Orientation Processes, Chemical Engineering Research and Design. 76 (1998) 38-44.

[3] Y. Marco, L. Chevalier, M. Chaouche, WAXD study of induced crystallization and orientation in poly (ethylene terephthalate) during biaxial elongation, Polymer. 43 (2002) 6569-6574.

[4] M. Vigny, J. Tassin, G. Lorentz, Study of the molecular structure of PET films obtained by an inverse stretching process Part 2: crystalline reorganization during longitudinal drawing, Polymer. 40 (1999) 397406.

[5] P. Chandran, S. Jabarin, Biaxial orientation of poly (ethylene terephthalate). Part I: Nature of the stressstrain curves, Advances in Polymer Technology. 12 (1993) 119-132.

[6] P. Chandran, S. Jabarin, Biaxial orientation of poly (ethylene terephthalate). Part III: Comparative structure and property changes resulting from simultaneous and sequential orientation, Advances in Polymer Technology. 12 (1993) 153-165.

[7] J.B. Faisant de Champchesnel, D.I. Bower, I.M. Ward, Development of molecular orientation in sequentially drawn PET films, Polymer. 34 (1993) 3763-3770.

[8] Y. Marco, L. Chevalier, Microstructure changes in poly(ethylene terephthalate) in thick specimens under complex biaxial loading, Polymer Engineering and Science. 48 (2008) 530-542.

[9] G.H. Menary, C.W. Tan, C.G. Armstrong, The Effect of Temperature, Strain Rate and Strain on the Induced Mechanical Properties of Biaxially Stretched PET, Key Engineering Materials. 504 (2012) 11171122.

[10] C.P. Buckley, D.C. Jones, Hot-drawing of poly(ethylene terephthalate) under biaxial stress application of a three-dimensional glass-rubber constitutive model, Polymer. 37 (1996) 2403-2414.

[11] C.P. Buckley, C.Y. Lew, Biaxial hot-drawing of poly(ethylene terephthalate): An experimental study spanning the processing range, Polymer. 52 (2011) 1803-1810.

[12] G. Menary, C. Tan, E. Harkin-Jones, C. Armstrong, P. Martin, Biaxial deformation and experimental study of PET at conditions applicable to stretch blow molding, Polymer Engineering and Science. 52 (2012) 671-688.

[13] P.J. Martin, C.W. Tan, K.Y. Tshai, R. McCool, G. Menary, C.G. Armstrong, et al., Biaxial characterisation of materials for thermoforming and blow moulding, Plastics, Rubber and Composites. 34 (2005) 276-282.

[14] C. Nagarajappa, Identification and validation of process parameters for stretch blow moulding simulation,PhD thesis, Queen's University Belfast. (2012). Chapter 6

[15] N. Billon, A. Erner, E. Gorlier, Kinematics of stretch blow moulding and plug assisted thermoforming of polymers: Experimental study, Polymer Porcessing Society. (2005).

[16] G. Menary, C. Tan, C. Armstrong, Y. Salomeia, M. Picard, N. Billon, et al., Validating injection stretchblow molding simulation through free blow trials, Polymer Engineering and Science. 50 (2010) 1047-1057.

[17] Deloye E.M Haudin J-M, Billon N., International Journal of Material Forming.1 (2008) 715-718.

[18] Zimmer et al., Key Engineering Materials. (2013) 1658-1668

[19] J. Nixon, G.H. Menary, S. Yan, Investigation into the free-stretch-blow process of poly(ethylene terephthalate). Part 1: Experimental analysis over a large process window, in press

[20] Y.M. Salomeia, G.H. Menary, C.G. Armstrong, Instrumentation and Modelling of the Stretch Blow Moulding Process, International Journal of Material Forming. 3 (2010) 591-594.

[21] S. Yan and G. H. Menary, Modelling the constitutive behaviour of PET for stretch blow moulding, The $14^{\text {th }}$ international ESAFORM conference on material forming, (2011).

[22] J. Nixon, G.H. Menary, S. Yan, Investigation into the free-stretch-blow process of poly(ethylene terephthalate). Part 2: Simulation validation, in press

[23] P.P. Benham, R.J. Crawford, C.G. Armstrong, Statically Determinate Stress Systems. Mechanics of Engineering Materials. (1996) 54.

[24] J.D. Lawrence, A Catalog of Special Plane Curves. New York: Dover. (1972) 4-5. 
[25] P. Purushothama Raj, V. Ramasamy, "Thick Cylinders and Shells" in Strength of Materials. (2012). Chapter 10

[26] S. Yan, Modelling the Constitutive Behaviour of Poly(ethylene terephthalate) for the Stretch Blow Moudling Process, PhD thesis, Queen's University Belfast. (2013), 150-157. 